\title{
Analysis on the situation of subjective well- being and its influencing factors in patients with ankylosing spondylitis
}

\author{
Mengmeng Wang ${ }^{1 \dagger}$, Sheng Wang ${ }^{1 \dagger}$, Xu Zhang ${ }^{1}$, Qing Xia ${ }^{1}$, Guoqi Cai ${ }^{1}$, Xiao Yang ${ }^{1}$, Xiaona Li ${ }^{1}$, Li Wang ${ }^{1}$, \\ Lihong $X i n^{1}$, Shengqian $X u^{2}$, Jianhua $X u^{2}$, Zongwen Shuai ${ }^{2}$ and Faming Pan $^{1 *}$ (D)
}

\begin{abstract}
Background: To examine the subjective well-being (SWB) in patients with ankylosing spondylitis (AS) compared with the healthy controls, and to explore the associations between SWB and demographic characteristics, disease-specific variables in AS patients.
\end{abstract}

Methods: SWB was assessed with General Well-Being Schedule (GWBS) in 200 AS patients and 210 healthy controls. Comparisons among subgroups were performed to investigate how certain aspects operate as favorable or adverse factors in influencing SWB in the patients with AS.

Results: Both men and women with AS reported significantly impaired SWB on all scales of the GWBS except for the Control (O) scale. The results revealed that better sleep, lower disease activity and more family care predicted higher SWB. In AS patients, positive attitude towards therapy prospect was significantly associated with higher SWB. Therapy prospect refers to the hope of patients about the disease treatment.

Conclusions: Compared with general population, SWB might be affected by the onset of AS. There are significant associations between SWB and sleep quality, BASDAI, APGAR, therapy prospect.

Keywords: Ankylosing spondylitis, Influencing factors, Subjective well-being

Abbreviations: AS, Ankylosing spondylitis; VAS, Visual analogue scale; BASDAI, Bath Ankylosing Spondylitis Disease Activity Index; BASFI, Bath Ankylosing Spondylitis Functional Index; APGAR, Adaptation, Partner-ship, Growth, Affection and Resolve; GWB, General well-being; SWB, Subjective well-being; HRQOL, Health-related quality of life

\section{Background}

Ankylosing spondylitis (AS) is a chronic inflammatory disease that affects the sacroiliac joints and spine of young adults, especially men (sex ratio 2:1) [1] and its prevalence is most commonly reported to be 0.1 to $1.4 \%$ depending on the population [2]. People who are affected generally present at around 26 years of age, typically have inflammatory back pain and structural damage, resulting in joint stiffness and a gradual loss of spinal mobility [2-4]. Male patients have more

\footnotetext{
* Correspondence: famingpan@ahmu.edu.cn

${ }^{\dagger}$ Equal contributors

'Department of Epidemiology and Biostatistics, School of Public Health, Anhui Medical University, 81 Meishan Road, Hefei, Anhui 230032, China Full list of author information is available at the end of the article
}

functional limitations and lower bone mineral density than female patients [5]. Because of the early onset, related work disability, absence from paid work and socioeconomic burden to individuals with AS are substantial especially men [6-8]. As these is no radical cure for AS patients at present, an important goal in treatment is to control the spinal inflammation and the resultant pain and stiffness [9].

Subjective well-being (SWB), a popular concept in positive psychology, has gained increasing attention in medical science [10]. Higher subjective well-being helps people to be more energetic, which is a vital component in recovery and treatment [11]. With increasing progress in improving functional capacity and survival in AS patients, it is becoming increasingly clear that, for 
many AS sufferers, improving the quality of life is equally as important as the survival benefit provided by pharmacological treatment. SWB refers to subjective and multidimensional evaluation of daily life [12, 13], which can be measured by the General Well-Being Schedule (GWBS). GWBS is a generic instrument, which covers the most central dimensions of subjective health and applies to diseased populations and healthy people. As we all know, there are many schedules regarding quality of life such as EuroQol (EQ-5D) or Short Form-36 (SF-36). However, the above schedules include physical components and mental components, which are used to reflect physical health and psychological health respectively $[14,15]$. Compared with EQ-5D or SF-36, the General Well-Being Schedule (GWBS) is a brief indicator of subjective feelings of psychological well-being and reflects mental health totally [16]. Furthermore, there are many studies about SF-36 evaluation in AS patients, but few about GWBS. Our team has verified the healthrelated quality of life of ankylosing spondylitis patients assessed by SF-36 [17]. Thus, we choose the GWBS in this current study.

The previous studies on subjective quality of life mainly aimed at healthy people, empirical knowledge on the subjective health of AS patients is relatively scarce. The aim of this study is to assess the SWB in patients with AS compared with the healthy controls, and to investigate the relationship of various domains of SWB with demographic characteristics, disease-specific variables in AS.

\section{Methods}

\section{Participants}

Patients with AS participating in this study were recruited from the Department of Rheumatology, the First Affiliated Hospital of Anhui Medical University between 2013 and 2014. There are 200 AS patients fulfilling the New York classification criteria [18]. A total of 210 sex and age matched healthy controls were collected from Physical Examination Center, the First Affiliated Hospital of Anhui Medical University.

\section{Data collection}

The study group included AS patients and healthy controls, they received a questionnaire including demographic variables, APGAR, some disease-specific instruments and a generic instrument (GWBS). SWB was assessed by the generic instrument (GWBS) in patients with AS and healthy controls. In healthy controls, it is unnecessary to complete the part of disease-specific instruments. All questionnaires were completed with the help of specialized training investigators. We obtained informed consent from all the patients and healthy controls and the study was approved by the ethical committee for medical research.

\section{Adaptation, Partner-ship, Growth, Affection and Resolve (APGAR)}

APGAR meaning satisfaction with family function was evaluated by the Family APGAR Index, which was compiled by Smilkstein, including 5 items: adaptation, partnership, growth, affection and resolve [19]. These five items corresponded to the following questions, I am satisfied that I can turn to my family for help when something is troubling me; I am satisfied with the way my family talks over things with me and shares problems with me; I am satisfied that my family accepts and supports my wishes to take on new activities or directions; I am satisfied with the way my family expresses affection and responds to my emotions; I am satisfied with the way my family and I share time together [19]. Each item has three response choices: "Often such" comments two points, "Sometimes this" comments one point, "rarely" comments 0 point. The five dimension scores were calculated, higher scores indicate better family function. Total score of 0-6 points represented a obstacle to family function and 7 to 10 meant good family function, so the AS sample can be divided into two compare groups in this current study.

\section{Generic instrument}

The GWBS is a generic instrument providing information about six aspects of SWB and it is widely used in health surveys in the general population [16]. This schedule contains 33 items-the first 14 items are 6 response option items rated on a 6-point scale, the next 4 items are $0-10$ rating bars scored on a 10-point scale, and the last 15 items are criterion-type behavioral and self-evaluation items [20]. Internal consistency coefficient of reliability for GWBS is 0.912 , which indicate that it is a homogeneous scale basically measuring a singular subscale or general subjective state [20]. In our study, we used the Chinese version of the General Well-Being Schedule putted forwarded by JH Duan [21]. After reversing the scoring on questions with high scores indicating negative attributes, the scores are summed for a total well-being score. Scoring for the first 18 items ranged from 14 to 116 with high scores signifying favorable responses [22]. This schedule assesses six hypothetical dimensions indicating $\mathrm{H}$ (Health, 2 items); E (Energy, 3 items); S (Satisfaction, 2 items); SH (Sad or Happy, 4 items); O (Control, 3 items); RT (Relaxation and Tension, 4 items).

\section{Disease-specific instruments}

The Bath Ankylosing Spondylitis Functional Index (BASFI) and the Bath Ankylosing Spondylitis Disease Activity Index (BASDAI) were used in AS for clinical and research purposes. The BASFI consists of eight visual analogue scales 
dealing with physical function and two scales reflecting the patient's ability to cope with daily activities [23]. The BASDAI consists of six visual analogue scales dealing with fatigue, spinal pain, joint pain, localized tenderness, and quality and quantity of morning stiffness (BASDAI and BASFI: $0=$ best, $100=$ worst score) [24]. BASFI $\geq 5$ means good function, so the AS samples are divided into two subgroups according to BASFI $\geq 5$ and BASFI $<5$. Similarly, BASDAI $\geq 4$ is defined as active stage. According to whether the value of BASDAI more than 4, the patients with AS are categorized into two groups. Visual Analog Scale (VAS), a numerical scale (11 points that initiate in 0 [no pain] and end in 10 [worst imaginable pain]), has been widely used in pain measurement of BASDAI [25]. This test has been certificated for a very long time and is widely accepted in many articles. It is reliable and easy to apply this scale in pain assessment.

\section{Statistical analyses}

All statistical tests were carried out using SPSS version 16.0 for Windows. First, the socio demographic and clinical variables were subjected to descriptive analysis. The numerical variables were expressed as means and standard deviations (SD), and the categorical variables were expressed as absolute and relative frequencies. Differences between patients and the healthy controls were examined by $\chi^{2}$ tests of categorical variables. IndependentSamples $t$-test was used to compare the mean scores of the GWB scales in the patient group and the general population. Within the patient group, two-sample $t$ tests or One-way ANOVA were used for comparisons. Multiple linear regression analyses were applied to study the predictors of SWB. The significant level was set at $p<0.05$.

\section{Results}

\section{Study samples}

The characteristics of samples are illustrated in Table 1 . The age of the healthy controls and the AS patients was comparable $(P=0.773)$, so was the sex ratio $(P=0.115)$. The proportion of physical workers was different, and the mean education level of the general population sample was higher than that of the AS sample $(P<0.001)$.

The patients reported significantly worse health on all scales of the GWB compared with the general population except for the Control (O) scale (Table 2 and Fig. 1).

The results of univariate analysis in the AS sample are shown in Table 3. Significant differences were found between physical workers and mental workers in the AS group for $\mathrm{H}$ scale $(p=0.015)$, SH scale $(p=0.034)$, with physical workers reporting worse health than mental workers (Table 3). Furthermore, there were significant correlations between the following variables and GWB scores, APGAR, life satisfaction, BASDAI, sleep quality, therapy
Table 1 Characteristics of patients with AS and the healthy controls

\begin{tabular}{|c|c|c|c|}
\hline Characteristics & AS $(n=200)$ & $\mathrm{HC}(n=210)$ & $P$ value \\
\hline Age (years), mean (SD) & $29.54(9.57)$ & $29.24(10.79)$ & 0.773 \\
\hline Men (\%) & $165(82.50)$ & $160(76.19)$ & 0.115 \\
\hline Occupation & & & $<0.001^{*}$ \\
\hline Mental workers (\%) & $93(46.50)$ & $167(79.52)$ & \\
\hline Physical workers (\%) & $107(53.50)$ & $43(20.48)$ & \\
\hline Educational level & & & $<0.001^{*}$ \\
\hline$\leq 12$ years $(\%)$ & $137(68.50)$ & $68(32.38)$ & \\
\hline$>12$ Years (\%) & $63(31.50)$ & $142(67.62)$ & \\
\hline Place of residence (\%) & & & 0.232 \\
\hline Rural residence & $120(60.00)$ & $113(53.80)$ & \\
\hline City residence (\%) & $80(40.00)$ & $97(46.20)$ & \\
\hline Family income & & & $0.005^{*}$ \\
\hline > $1500(\%)$ & $133(66.50)$ & $167(79.52)$ & \\
\hline$\leq 1500(\%)$ & $66(33.00)$ & $43(20.48)$ & \\
\hline Sleep quality & & & $<0.001^{*}$ \\
\hline Better (\%) & $60(30.00)$ & $89(42.38)$ & \\
\hline General (\%) & $93(46.50)$ & $100(47.62)$ & \\
\hline Poor (\%) & $47(23.50)$ & $21(10.00)$ & \\
\hline Life Satisfaction & & & 0.051 \\
\hline Particularly Satisfied (\%) & $13(6.50)$ & $26(12.38)$ & \\
\hline Satisfied (\%) & $145(72.50)$ & $153(72.86)$ & \\
\hline Not Satisfied (\%) & $42(21.00)$ & $31(14.76)$ & \\
\hline \multicolumn{4}{|c|}{ Therapy Prospect (attitudes toward therapy) } \\
\hline Very Optimistic (\%) & $14(7.0)$ & & \\
\hline Optimistic (\%) & $84(42.0)$ & & \\
\hline General (\%) & $84(42.0)$ & & \\
\hline Poor (\%) & $13(6.5)$ & & \\
\hline No Hope (\%) & $5(2.5)$ & & \\
\hline \multicolumn{4}{|l|}{ Disease duration } \\
\hline$\leq 5$ years $(\%)$ & $134(67.00)$ & & \\
\hline$>5$ years $(\%)$ & $66(33.00)$ & & \\
\hline APGAR, mean (SD) & $6.95(2.25)$ & & \\
\hline BASDAl, mean (SD) & $2.71(2.03)$ & & \\
\hline BASFI, mean (SD) & $1.68(1.94)$ & & \\
\hline
\end{tabular}

AS ankylosing spondylitis, HC healthy controls, APGAR Adaptation, Partner-ship, Growth, Affection and Resolve, BASDAl Bath Ankylosing Spondylitis Disease Activity Index, BASFI Bath Ankylosing Spondylitis Functional Index, mean average value, $S D$ standard deviation ${ }^{*} P<0.05$

prospects and place of residence with $\mathrm{E}$ (All $P<0.05$ ); place of residence, life satisfaction, therapy prospects, APGAR, and educational level with $S$ (All $P<0.05$ ); All variables except educational level have been found to be correlated with $\mathrm{SH}($ All $P<0.05)$. Therapy prospects and BASDI were associated with $\mathrm{O}(P=0.037, P<0.001)$. 
Table 2 Summary of GWB domains

\begin{tabular}{llll}
\hline Subscale & AS, mean (SD) & HC, mean (SD) & $P$ value \\
\hline H & $6.25(2.04)$ & $7.67(2.37)$ & $<0.001$ \\
E & $13.81(3.23)$ & $14.60(3.21)$ & 0.014 \\
S & $6.17(1.40)$ & $6.50(1.23)$ & 0.013 \\
SH & $18.41(3.91)$ & $19.63(3.39)$ & 0.001 \\
O & $10.78(1.99)$ & $10.02(1.95)$ & $<0.001$ \\
RT & $15.57(3.25)$ & $17.90(3.47)$ & $<0.001$ \\
Total Score & $70.98(11.12)$ & $76.30(9.48)$ & $<0.001$ \\
\hline AS Anky)
\end{tabular}

AS Ankylosing Spondylitis, $H C$ healthy controls, $H$ Health, $E$ Energy, $S$ satisfaction, $S H$ Sad or Happy, O control, RT Relaxation and Tension, mean average value, $S D$ standard deviation

There are statistical correlations between RT and sleep quality, life satisfaction, therapy prospects, APGAR, BASDAI $(P<0.05)$. Furthermore, total score was positively related to APGAR $(P<0.001)$. It was negatively related to BASDAI $(P<0.001)$ and BASFI $(P=0.044)$. Sleep quality was also significant $(P<0.001)$, with better sleep showing higher SWB than worse sleep. Life satisfaction and therapy prospects were negatively related to SWB (All $P<0.001$ ).

\section{Multiple linear regression analyses}

Multivariable linear regression analysis showed that the following variables were significantly associated with the score of six subscales: Occupation, BASDAI, Life satisfaction and Sleep quality with $\mathrm{H}$ (All $P<0.05)$; Sleep quality,therapy prospects APGAR and BASDAI with $\mathrm{E}$ (All $P<0.05)$; life satisfaction $(P=0.002)$, therapy pros-

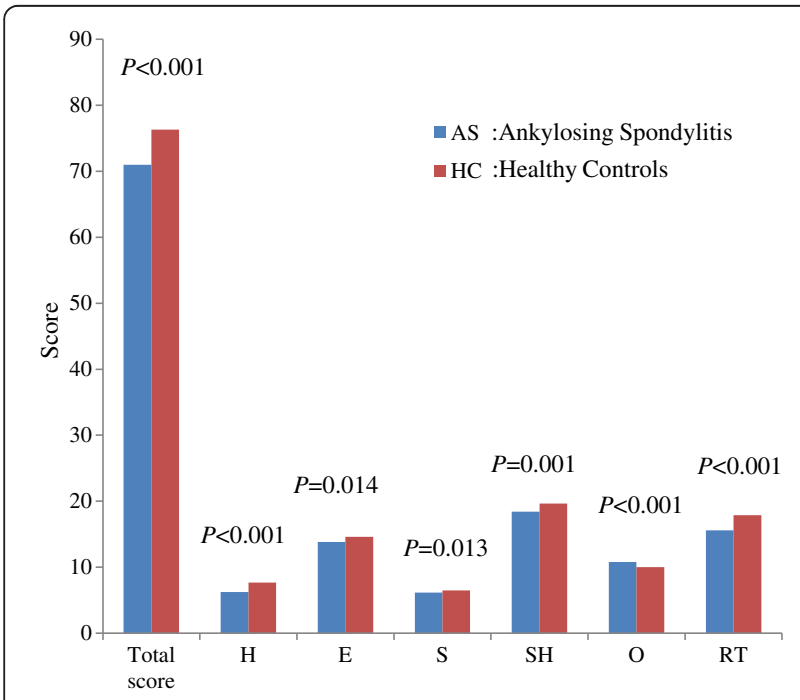

Fig. 1 The comparison for each of the subscales between AS patients and healthy controls pects $(P=0.039)$, APGAR $(P=0.019)$ with $S$; Life satisfaction $(P=0.038)$, therapy prospects $(P<0.001)$, Sleep quality $(P=0.013)$ APGAR $(P<0.001)$, BASDAI $(P=0.010)$ with SH; BASDAI $(P=0.013)$ with $\mathrm{O}$; therapy prospects $(P=0.002)$, APGAR $(P=0.001)$, BASDAI $(P=0.001)$ with RT.

However, final multivariable linear regression analysis with total score as dependent variable included four predictors (see Table 4). The significant model obtained, revealed that better sleep, lower disease activity and more family care predicted higher SWB. Therapy prospect was also a significant predictor in this model with positive attitudes reporting higher well-being than negative attitudes.

\section{Discussion}

In this study, we aimed to determine which variables affect the SWB assessed by GWBS survey in AS patients. The significant correlation in the AS group was obtained between the four variables (sleep quality, Family-APGAR, BASDAI, therapy prospect) and SWB.

Firstly, in this Subjective Well-being survey, patients with AS reported significantly impaired health on all scales of GWB except for the O scale, compared with the healthy controls. Age and sex ratio are comparable in the two samples, thus, we consider that SWB may be affected by the AS disease.

Secondly, the results of single factor analysis in the AS patients indicated that SWB may differ significantly between two subgroups of residence. In addition, the SWB of physical workers differed significantly from the SWB of mental workers. However, when analyzing demographic variables in the healthy population, age, marital status, family income and occupation have been found to be associated with the total score of SWB $(P=0.004, P=0.001$, $P=0.003, P=0.013)$. That is to say, demographic variables do not appear to have much of an impact on SWB in the AS patients, which is consistent with the previous study in healthy people [26]. Study on patients attending community-based mental health services reported that demographic variables explained only $2.9 \%$ of the variance in subjective quality of life [27].

Thirdly, the regression analyses revealed that subjective well-being was positively associated with better sleep, lower disease activity and more family care, therapy prospect. Occupation and place of residence were excluded from the regression equation, which highlighted the fact that demographic variables did not play a crucial role in the well-being of AS patients.

We observed that $23.5 \%$ of participants suffered from sleep disorder, and sleep quality, which should not be ignored, has been found to affect SWB in AS patients. In addition, some results have also been reported that there was a higher rate of sleep disturbance in patients with AS $[28,29]$, which were important concerns in patients 
Table 3 The results of univariate analysis in AS group (shown as $P$ value)

\begin{tabular}{llllllll}
\hline Predictors & $\mathrm{H}$ & $\mathrm{E}$ & $\mathrm{S}$ & $\mathrm{SH}$ & $\mathrm{O}$ & $\mathrm{RT}$ & Total score \\
\hline Occupation & $0.015^{*}$ & 0.067 & 0.113 & $0.034^{*}$ & 0.166 & 0.533 & 0.142 \\
Place of residence & 0.593 & $0.048^{*}$ & $0.041^{*}$ & $0.028^{*}$ & 0.203 & 0.395 & $0.047^{*}$ \\
Educational level & 0.742 & 0.425 & $0.014^{*}$ & 0.135 & 0.769 & 0.776 & 0.330 \\
Life satisfaction & 0.103 & $<0.001^{*}$ & $<0.001^{*}$ & $<0.001^{*}$ & 0.504 & $0.001^{*}$ & $<0.001^{*}$ \\
Therapy Prospect & 0.231 & $0.002^{*}$ & $0.020^{*}$ & $0.020^{*}$ & $0.037^{*}$ & $<0.001^{*}$ & $<0.001^{*}$ \\
Sleep quality & 0.274 & $<0.001^{*}$ & 0.192 & $0.001^{*}$ & 0.320 & $0.046^{*}$ & $<0.001^{*}$ \\
Duration disease & 0.599 & 0.131 & 0.528 & $0.016^{*}$ & 0.186 & 0.788 & 0.191 \\
APGAR & 0.181 & $<0.001^{*}$ & $0.011^{*}$ & $<0.001^{*}$ & 0.777 & $<0.001^{*}$ & $<0.001^{*}$ \\
BASDAI & 0.153 & $<0.001^{*}$ & 0.060 & $<0.001^{*}$ & $<0.001^{*}$ & $<0.001^{*}$ & $<0.001^{*}$ \\
BASFI & 0.896 & 0.306 & 0.480 & $0.006^{*}$ & 0.162 & 0.194 & $0.044^{*}$ \\
\hline
\end{tabular}

$H$ Health, E Energy, S satisfaction, SH Sad or Happy, O control, RT Relaxation and Tension

${ }^{*} P<0.05$

with AS [30]. In agreement with these findings, recent studies [31, 32] have suggested that poor sleep can impair well- being, most of these studies have involved individuals' perceptions of sleep quality and duration. However, Jean-Louis and colleagues [33] found no association between sleep quality and SWB in adult general population. Sleep disturbance is often produced by inflammatory pain $[5,34]$. Also, mental as well as physical aspects were affected due to the poor sleep quality [35]. Consequently, it is not hard to follow the relationship between sleep quality and SWB in this study. We all know that, poor sleep quality can aggravate the patients' condition, which is unfavorable for the recovery of the disease. Sleep disturbance is frequently complained by patients with AS and is still largely ignored by clinical care and research [36]. Thus, we should pay great attention to the patients' quality of sleep, to examine the independent risk factors of sleep quality and to improve sleep quality in AS patients.

Family function is what family performs on the behalf of its members in a larger society and it is assessed by APGAR [37]. In our study, family function appeared to be related to SWB in AS patients. Previous study suggested that family function had much effect on quality of life and well-being [37]. Likewise, Andrea reported that family ties had significant and positive associations with psychological well-being [38]. Kenneth et al. [39] also confirmed that family function in women with rheumatoid arthritis is related to subjective well-being, beyond the pain and fatigue associated with SWB. To our knowledge, Family care or Family-APGAR to some extent can help us cope with stress, anxiety and various emergencies, which could influence SWB. It should be considered as a determinant of health to improve subjective well-being. In addition, BASDAI has a negative relationship with the variable of subjective well-being. BASDAI addresses disease activity which definitely affects quality of life, thereby, it is reasonable to draw such a conclusion. The conclusion is highly consistent with Bing Han's research indicating functional capacity as predictor of psychological health [40], as well as the study of Geertzen which concluded that the influence on SWB was less when patients were physically independent [41]. Based on the findings of the present study, positive attitudes towards therapy prospect leads to higher well-being of the patients with AS. To our knowledge, it is necessary to stay positive and then to be helpful to our state of mind.

Table 4 Multivariable linear analysis of association between demographics, APGAR and BASDAI with the GWB

\begin{tabular}{|c|c|c|c|c|c|c|c|c|c|c|c|c|c|c|}
\hline \multirow[t]{2}{*}{ Predictors } & \multicolumn{2}{|l|}{$\mathrm{H}$} & \multicolumn{2}{|l|}{$E$} & \multicolumn{2}{|l|}{ S } & \multicolumn{2}{|l|}{$\mathrm{SH}$} & \multicolumn{2}{|l|}{$\mathrm{O}$} & \multicolumn{2}{|l|}{ RT } & \multirow{2}{*}{$\begin{array}{l}\text { Total } \\
\beta\end{array}$} & \multirow{2}{*}{$\begin{array}{l}\text { Score } \\
P\end{array}$} \\
\hline & $\beta$ & $P$ & $\beta$ & $P$ & $\beta$ & $P$ & $\beta$ & $P$ & $\beta$ & $P$ & $\beta$ & $P$ & & \\
\hline Occupation & 0.822 & $0.005^{*}$ & -0.464 & 0.643 & -0.057 & 0.398 & -0.033 & 0.596 & -0.076 & 0.288 & 0.040 & 0.544 & 0.015 & 0.805 \\
\hline Life satisfaction & 0.879 & $0.003^{*}$ & -1.130 & 0.260 & -0.618 & $0.002^{*}$ & -1.033 & $0.038^{*}$ & -0.049 & 0.501 & -0.125 & 0.070 & -0.088 & 0.182 \\
\hline Therapy Prospect & -0.018 & 0.808 & -0.775 & $0.002^{*}$ & -0.250 & $0.039^{*}$ & -1.288 & $<0.001^{*}$ & -0.113 & 0.118 & -0.808 & $0.002^{*}$ & -3.410 & $<0.001^{*}$ \\
\hline Sleep quality & -0.435 & $0.032^{*}$ & -1.052 & $<0.001^{*}$ & -0.042 & 0.546 & -0.827 & $0.013^{*}$ & -0.038 & 0.595 & -0.091 & 0.174 & -2.915 & $0.002^{*}$ \\
\hline APGAR & 0.084 & 0.231 & 0.315 & $0.001^{*}$ & 0.103 & $0.019^{*}$ & 0.395 & $<0.001^{*}$ & -0.023 & 0.746 & 0.324 & $0.001^{*}$ & 1.158 & $<0.001^{*}$ \\
\hline BASDAI & -0.158 & $0.032^{*}$ & -0.211 & $0.047^{*}$ & -0.086 & 0.222 & -0.313 & $0.010^{*}$ & -0.176 & $0.013^{*}$ & -0.352 & $0.001^{*}$ & -1.192 & $0.001^{*}$ \\
\hline
\end{tabular}

APGAR Adaptation, Partner-ship, Growth, Affection and Resolve, BASDAI Bath Ankylosing Spondylitis Disease Activity Index, $H$ Health, $E$ Energy, $S$ satisfaction, SH Sad or Happy, O control, RT Relaxation and Tension ${ }^{*} P<0.05$ 
Lastly, there are some limitations of our study. First, we recruited AS patients from one hospital, even though the hospital has a wide audience in the province, findings of this study cannot be generalized to all AS patients in our society. Second, it was a cross-sectional design and therefore can only be used to draw conclusions based on the relationships among variables. Longitudinal studies should be performed to identify the effects found in the present study. Third, although we have found sleep quality had significant correlations with SWB, many influencing factors of sleep quality should be explored. Last, we did not consider the relationship between SWB and kinds of drugs patients accepted, which should be verified in further studies.

\section{Conclusions}

SWB was significantly associated with sleep quality, therapy prospects, APGAR and BASDAI. It is important for clinicians to be aware of complicated relationships between clinical variables and SWB. In order to perfect AS patients' SWB, current management strategies should focus on reducing disease activity, improving sleep quality and family ties.

\section{Acknowledgements}

The study was supported by grants from the National Natural Science Foundation of China $(30771849,30972530,81273169,81573218$, and 81571572). The authors would like to thank Anhui Medical University for providing samples for the study. The authors would also like to thank the participants who cooperate with our team.

\section{Funding}

The study was supported by grants from the National Natural Science Foundation of China (30771849, 30972530, 81273169, 81573218, 81571572) and Natural Science key project of Anhui province education department (KJ2014A127).

\section{Availability of data and materials}

All data and figure have been presented in the main paper and additional supporting files. We agree that the data could be shared.

\section{Authors' contributions}

MW was responsible for the design and conduct of the statistical analysis, the interpretation of data and the drafting of the manuscript. SW helped to the conception of the questionnaire and the revision of the manuscript. $X Z$, QX, GC, XY, XL, LW and LX were responsible for data collection. SX, JX and ZS helped to search for eligible patients and controls. FP participated in the process. All authors read and approved the final manuscript.

\section{Competing interests}

The authors declare that they have no competing interests.

\section{Consent for publication}

Not applicable.

\section{Ethics approval and consent to participate}

We obtained informed consent from all the patients and healthy controls and the study was approved by the ethical committee for medical research.

\section{Author details}

${ }^{1}$ Department of Epidemiology and Biostatistics, School of Public Health, Anhui Medical University, 81 Meishan Road, Hefei, Anhui 230032, China. ${ }^{2}$ Department of Rheumatism and Immunity, the First Affiliated Hospital of Anhui Medical University, Hefei, Anhui 230022, China.
Received: 20 March 2016 Accepted: 16 August 2016

Published online: 22 August 2016

\section{References}

1. Montoya J, Matta NB, Suchon P, et al. Patients with ankylosing spondylitis have been breast fed less often than healthy controls: a case-control retrospective study. Ann Rheum Dis. 2015; doi:10.1136/annrheumdis-2015-208187.

2. Braun J, Sieper J. Ankylosing spondylitis. Lancet. 2007;369:1379-90.

3. Dagfinrud H, Mengshoel AM, Hagen KB, Loge JH, Kvien TK. Health status of patients with ankylosing spondylitis: a comparison with the general population. Ann Rheum Dis. 2004;63:1605-10.

4. Will R, Palmer R, Bhalla AK, Ring F, Calin A. Osteoporosis in early ankylosing spondylitis: a primary pathological event? Lancet. 1989;2:1483-5.

5. Aydin T, Karacan I, Demir SE, Sahin Z. Bone loss in males with ankylosing spondylitis: its relation to sex hormone levels. Clin Endocrinol (Oxf). 2005;63:467-9.

6. Boonen A. Socioeconomic consequences of ankylosing spondylitis. Clin Exp Rheumatol. 2002;20 Suppl 28:23-6.

7. Boonen A, van der Heijde D, Landewe R, et al. Work status and productivity costs due to ankylosing spondylitis: comparison of three European countries. Ann Rheum Dis. 2002;61:429-37.

8. Rkain H, Allali F, Bentalha A, Lazrak N, Abouqal R, Hajjaj-Hassouni N. Socioeconomic impact of ankylosing spondylitis in Morocco. Clin Rheumatol. 2007;26:2081-8.

9. Braun J, Brandt J, Listing J, et al. Treatment of active ankylosing spondylitis with infliximab: a randomised controlled multicentre trial. Lancet. 2002;359:1187-93.

10. Zhao F, Guo Y, Suhonen R, Leino-Kilpi H. Subjective well-being and its association with peer caring and resilience among nursing vs medical students: a questionnaire study. Nurse Educ Today. 2016;37:108-13.

11. Ratanasiripong $P$, Ratanasiripong N, Kathalae D. Biofeedback intervention for stress and anxiety among nursing students: a randomized controlled trial. ISRN Nurs. 2012;2012:827972.

12. Perez-Garcia AM, Olivan S, Bover R. Subjective well-being in heart failure patients: influence of coping and depressive symptoms. Int J Behav Med. 2014;21:258-65.

13. Nes RB, Roysamb E, Reichborn-Kjennerud T, Tambs K, Harris JR. Subjective wellbeing and sleep problems: a bivariate twin study. Twin Res Hum Genet. 2005;8:440-9.

14. Zhu YX, Li T, Fan SR, Liu XP, Liang YH, Liu P. Health-related quality of life as measured with the Short-Form 36 (SF-36) questionnaire in patients with recurrent vulvovaginal candidiasis. Health Qual Life Outcomes. 2016;14:65.

15. van de Willige G, Wiersma D, Nienhuis FJ, Jenner JA. Changes in quality of life in chronic psychiatric patients: a comparison between EuroQol (EQ-5D) and WHOQoL. Qual Life Res. 2005;14:441-51.

16. Leonardson GR, Daniels MC, Ness FK, et al. Validity and reliability of the general well-being schedule with northern plains American Indians diagnosed with type 2 diabetes mellitus. Psychol Rep. 2003;93:49-58.

17. Yang X, Fan D, Xia Q, et al. The health-related quality of life of ankylosing spondylitis patients assessed by SF-36: a systematic review and metaanalysis. Qual Life Res. 2016. doi:10.1007/s11136-016-1345-z.

18. Raychaudhuri SP, Deodhar A. The classification and diagnostic criteria of ankylosing spondylitis. J Autoimmun. 2014;48-49:128-33.

19. Bellon Saameno JA, Delgado Sanchez A, del Luna Castillo JD, Lardelli Claret P. Validity and reliability of the family Apgar family function test. Aten Primaria. 1996:18:289-96

20. Fazio AF. A concurrent validational study of the NCHS General Well-Being Schedule. Vital Health Stat 2. 1977. http://www.cdc.gov/nchs/data/series/sr_ 02/sr02_073.pdf.

21. Duan J. Analysis of the general well-being scale test results in the Chinese Students. Chinese Journal of Clinical Psychology. 1996;4:56-7.

22. Nakayama T, Toyoda H, Ohno K, Yoshiike N, Futagami T. Validity, reliability and acceptability of the Japanese version of the General Well-Being Schedule (GWBS). Qual Life Res. 2000;9:529-39.

23. Zochling J, Braun J. Assessments in ankylosing spondylitis. Best Pract Res Clin Rheumatol. 2007;21:699-712.

24. Garrett S, Jenkinson T, Kennedy LG, Whitelock H, Gaisford P, Calin A A new approach to defining disease status in ankylosing spondylitis: the Bath Ankylosing Spondylitis Disease Activity Index. J Rheumatol. 1994;21:2286-91. 
25. Averbuch M, Katzper M. Assessment of visual analog versus categorical scale for measurement of osteoarthritis pain. J Clin Pharmacol. 2004;44:368-72.

26. Deeming C. Addressing the social determinants of subjective wellbeing: the latest challenge for social policy. J Soc Policy. 2013:42:541-65.

27. Ruggeri M, Gater R, Bisoffi G, Barbui C, Tansella M. Determinants of subjective quality of life in patients attending community-based mental health services. The South-Verona Outcome Project 5. Acta Psychiatr Scand. 2002;105:131-40.

28. Aissaoui N, Rostom S, Hakkou J, et al. Fatigue in patients with ankylosing spondylitis: prevalence and relationships with disease-specific variables, psychological status, and sleep disturbance. Rheumatol Int. 2012;32:2117-24.

29. Gunaydin R, Goksel Karatepe A, Cesmeli N, Kaya T. Fatigue in patients with ankylosing spondylitis: relationships with disease-specific variables, depression, and sleep disturbance. Clin Rheumatol. 2009;28:1045-51.

30. Ward MM. Health-related quality of life in ankylosing spondylitis: a survey of 175 patients. Arthritis Care Res. 1999;12:247-55.

31. Lemola S, Ledermann T, Friedman EM. Variability of sleep duration is related to subjective sleep quality and subjective well-being: an actigraphy study. PLoS One. 2013;8:e71292

32. Lund $H G$, Reider $B D$, Whiting $A B$, Prichard JR. Sleep patterns and predictors of disturbed sleep in a large population of college students. J Adolesc Health. 2010:46:124-32.

33. Jean-Louis G, Kripke DF, Ancoli-Israel S. Sleep and quality of well-being. Sleep. 2000;23:1115-21.

34. Maksymowych WP, Gooch KL, Wong RL, Kupper H, van der Heijde D. Impact of age, sex, physical function, health-related quality of life, and treatment with adalimumab on work status and work productivity of patients with ankylosing spondylitis. J Rheumatol. 2010;37:385-92

35. Ibn Yacoub Y, Amine B, Laatiris A, Abouqal R, Hajjaj-Hassouni N. Healthrelated quality of life in Moroccan patients with ankylosing spondylitis. Clin Rheumatol. 2011;30:673-7.

36. Hakkou J, Rostom S, Mengat M, Aissaoui N, Bahiri R, Hajjaj-Hassouni N. Sleep disturbance in Moroccan patients with ankylosing spondylitis: prevalence and relationships with disease-specific variables, psychological status and quality of life. Rheumatol Int. 2013;33:285-90.

37. Farajzadegan Z, Koosha P, Sufi GJ, Keshvari M. The relationship between family function and women's well-being. Iran J Nurs Midwifery Res. 2013;18:9-13

38. Ryan AK, Willits FK. Family ties, physical health, and psychological wellbeing. J Aging Health. 2007;19:907-20.

39. Coty MB, Wallston KA. Problematic social support, family functioning, and subjective well-being in women with rheumatoid arthritis. Women Health. 2010:50:53-70.

40. Han B, Yan B, Zhao N, et al. The influence of the functional capacity on subjective well-being and quality of life of patients with silicosis. Aging Ment Health. 2013;17:707-13.

41. Bosmans JC, Suurmeijer TP, Hulsink M, van der Schans $C P$, Geertzen JH, Dijkstra PU. Amputation, phantom pain and subjective well-being: a qualitative study. Int J Rehabil Res. 2007;30:1-8.

\section{Submit your next manuscript to BioMed Central and we will help you at every step:}

- We accept pre-submission inquiries

- Our selector tool helps you to find the most relevant journal

- We provide round the clock customer support

- Convenient online submission

- Thorough peer review

- Inclusion in PubMed and all major indexing services

- Maximum visibility for your research

Submit your manuscript at www.biomedcentral.com/submit

) Biomed Central 